\title{
BIM and Public Bidding in Brazil
}

\author{
Eduardo Sampaio Nardelli \\ Universidade Presbiteriana Mackenzie| Brazil | nardelli@mackenzie.br
}

SIGRADI2018 TECHNOPOLITICAS

xxii congresso da sociedade iberoamericana de gráfica digital 22th conference of the iberoamerican society of digital graphics $07|08| 09 \mid$ novembro|2018 iau usp | são carlos | sp br

\begin{abstract}
This paper aims to describe and comment on recent advances in the adoption of BIM in Brazilian public bids. We give a brief account of this trajectory, in all its aspects and we analyze the recent federal decree 9377/18 that created a national strategy for the implementation of BIM in the public sector and compare it with the current regulatory background and the recessive momentum of AEC sector in Brazil.
\end{abstract}

Keywords: BIM; Public bidding; Brazilian regulation framework; Brazilian architectural design; Brazilian building environment.

\section{INTRODUÇÃO}

A adoção do processo BIM - Building Information Modeling no Brasil corresponde a uma longa trajetória, que se iniciou na primeira década dos anos 2000, seguindo a tendência internacional.

Esta trajetória, no entanto, tem sido errática, de vez que seus avanços e recuos estão intimamente ligados às oscilações da atividade econômica no Brasil, particularmente, no que se refere à indústria da construção civil.

De fato, o BIM ganhou destaque no país quando o crescimento do mercado imobiliário brasileiro, no início da década passada, somado ao lançamento do Programa Minha Casa Minha Vida - PMCMV contribuíram decisivamente para o aumento da complexidade de gestão no setor. (Nardelli, 2012)

Neste processo, ao ampliar a abrangência territorial de sua atuação pelo país, várias empresas enfrentaram o desafio de gerenciar centenas de empreendimentos concomitantes a distâncias continentais entre si, sujeitos a diferentes legislações urbanas e normas locais para licenciamento de projetos, bem como realidades diversas de custos de material e mão de obra, compondo, sem dúvida, um complexo cenário de governança e gestão.

Neste contexto, o processo BIM passou a ser visto como recurso essencial para garantir a assertividade dos resultados previstos nos empreendimentos, desde os estudos de viabilidade e projetos elaborados na fase de concepção e estruturação do investimento até o lançamento do produto no mercado e consequente gestão de sua construção. (SECOVI, 2011)

Como resultado, desencadeou-se pelo país uma verdadeira onda BIM, com a realização de vários eventos de disseminação desse conhecimento, estruturação de pesquisas nas universidades e de grupos de trabalho nas entidades representativas do setor, articulados entre si e com as agências governamentais de fomento à pesquisa e instâncias de definição de políticas setoriais, como o MDIC - Ministério do Desenvolvimento, Indústria e
Comércio e o, então, MCT - Ministério da Ciência e Tecnologia, tendo como objetivo principal a adoção deste novo processo de produção de projetos no Brasil.

Como parte deste esforço, em 2008 foi criado em São Paulo um Grupo de Trabalho interdisciplinar que reuniu as entidades representativas da cadeia produtiva da construção civil brasileira, incluindo algumas companhias incorporadoras do setor imobiliário, que deu início a um processo de disseminação sistemática do BIM no Brasil, através de várias ações coordenadas, como workshops e seminários, que contaram com relatos de alguns casos de sucesso brasileiros, além de contribuições de palestrantes estrangeiros. (Nardelli e Tonso, 2014)

Boa parte desse grupo constituiu, um ano depois, o colegiado da Comissão de Estudo Especial ABNT/CEE134, criada por iniciativa do MDIC para definir as regras, diretrizes e características da Modelagem de Informação da Construção (BIM), que elaborou a primeira versão da NBR ISO 12006-2:2018, Organização da Informação da Construção, complementada pelas NBR 15965- 1, 2, 3 e 7:2015

Acompanhando esta tendência as contratações em âmbito governamental passaram a se interessar também em incorporar o novo processo de concepção e desenvolvimento de projetos, publicando editais de licitações que exigiam a utilização do BIM para o desenvolvimento dos produtos contratados sem, no entanto, definirem claramente no termo de referência, o que seria este BIM.

Lacuna que seria superada pelo lançamento, em março de 2014, do "Termo de Referência para desenvolvimento de projetos com o uso da Modelagem da Informação da Construção (BIM)", elaborado pela Secretaria de Estado da Saúde de Santa Catarina.

Um exaustivo trabalho, que explicita detalhadamente todo o processo BIM, desde as definições básicas do que é a Modelagem da Informação da Construção até as diretrizes, etapas e respectivos produtos, dando à empresa contratada a possibilidade desenvolver o projeto com o software de sua preferência, porém com o 
compromisso de entregar os arquivos finais também no formato universal IFC, entendido ali como a "extensão pública" para o Gerenciamento e Interoperabilidade de informações e dados de projeto. (Santa Catarina, 2014)

Justamente naquele momento, a economia brasileira entrava em crise, praticamente paralisando as atividades do mercado imobiliário e as contratações públicas de projetos e obras, com importantes reflexos na dinâmica de implementação do processo BIM nas empresas de AEC do país, em particular com a demissão em massa de milhares de trabalhadores do setor. (G1.Globo.com, 2015)

Neste contexto, as equipes que compunham os núcleos de implementação do BIM em grandes e médias empresas foram desmobilizadas e muitos de seus integrantes desligados do quadro de funcionários, levando consigo para suas novas atividades profissionais a cultura adquirida nestas empresas, contribuindo desse modo, paradoxalmente, para a disseminação do conhecimento BIM. Enquanto outros têm buscado capacitar-se neste período ocioso, visando a novas oportunidades no futuro. (Toledo, 2018)

No entanto, enquanto o mercado se retraía, a atividade institucional prosseguiu no esforço de atualização e complementação das Normas em elaboração na Comissão de Estudo Especial ABNT/CEE-134 e através de novas iniciativas.

Dentre elas, vale citar a assinatura de um MoU Memorando de Entendimento - entre o Ministério do Comércio Internacional do Reino Unido e o MDIC prevendo a troca de informações sobre as estratégias de cada país para disseminar a tecnologia BIM, que impulsionou a criação de uma agenda nacional para adoção deste processo nas contratações do setor público brasileiro, liderada por este Ministério. (UK, 2016)

Ação pública, que sensibilizou o setor privado, atraindo importantes entidades, como a Câmara Brasileira da Indústria da Construção - CBIC que aderiu à iniciativa oficial e, em 2016, publicou a "COLETÂNEA IMPLEMENTAÇÃO DO BIM PARA CONSTRUTORAS E INCORPORADORAS", com 5 volumes abrangendo desde os fundamentos do que é BIM até as formas de contratação, além de um guia orientativo, apresentando "10 Motivos para Evoluir com BIM" (CBIC, 2016) que se somou ao pioneiro "Guia AsBEA de Boas Práticas em BIM" (AsBEA, 2013), em dois fascículos, lançado 3 anos antes, como contribuição do setor privado de AEC à disseminação deste conhecimento.

Em 2017, a Agência Brasileira de Desenvolvimento Industrial - ABDI, vinculada do MDIC, lançou a "Coletânea Guias BIM ABDI-MDIC", um conjunto de seis Guias orientativos sobre o processo BIM, desde as suas definições básicas até as recomendações para a sua implantação nas empresas e demais instituições contratantes. Um valioso apoio à adoção desse processo pelo setor público. (ABDI, 2017)

Por outro lado, o avanço das investigações sobre a corrupção nas contratações públicas brasileiras, em particular as de obras, consolidou na sociedade e entre os profissionais de AEC a expectativa pela adoção de processos transparentes e assertivos, capazes de evitar desvios dos escassos recursos financeiros do Estado e irregularidades na gestão de empresas públicas.

Esta expectativa teve como resposta diversas ações do governo federal, como a Lei 13.303 de 30/06/16, conhecida como Lei das Estatais por disciplinar o estatuto jurídico das empresas públicas, inclusive as regras para licitações e o Decreto14.473/2017, de 05/06/2017, criando o Comitê Estratégico de Implementação do BIM CE-BIM, um grupo interministerial coordenado pelo Ministério da Indústria, Comércio Exterior e Serviços MDIC, com a participação de vários outros ministérios e de consultores, especialistas e pesquisadores ad hoc. (SINAENCO, 2018)

Em praticamente um ano de trabalho este Comitê logrou aprofundar o tema, através de Grupos de Trabalho específicos, viabilizando a edição do Decreto 9.377 de 17/05/18, que institui a "Estratégia Nacional de Disseminação do Building Information Modelling no Brasil - Estratégia BIM BR", que tem por objetivo “(...)promover um ambiente adequado ao investimento em Building Information Modelling - BIM e sua difusão no País(...)" estabelecendo, desse modo, o instrumento institucional e os objetivos específicos para a definição de uma agenda de implementação do BIM no setor público brasileiro. (Brasil, 2018)

Que resultados podem ser esperados a partir de agora?

De um lado, há todo um conjunto de regulações - leis, decretos e normas - que precisam ser aperfeiçoados ou minimamente adaptados à pretendida "Estratégia BIM $B R$ ”, de outro, há todo um setor, público e privado, que precisa se capacitar, adequando-se às peculiaridades do processo BIM, justamente no momento em que há poucas contratações e, portanto, grande escassez de recursos financeiros para dar suporte ao esforço correspondente a esta demanda.

São estas questões que aprofundamos a seguir.

\section{DECRETO 9.377/18}

O Decreto 9.377 de 17 de maio de 2018 é o resultado do esforço concentrado da equipe interministerial e consultores ad hoc, que se reuniu a partir do Decreto 14.473/2017, de 05 de junho de 2017, que criou o Comitê Estratégico de Implementação do Building Information Modelling - CE-BIM.

No caput do Art.1ํ. institui a Estratégia Nacional de Disseminação do Building Information Modelling no Brasil - Estratégia BIM BR, para promover um ambiente adequado ao investimento em BIM e sua difusão no País, definindo BIM - ou Modelagem da Informação da Construção - no Parágrafo Único, como o conjunto de tecnologias e processos integrados que permite a criação, a utilização e a atualização de modelos digitais de uma construção, de modo colaborativo, de forma a servir a todos os participantes do empreendimento, potencialmente durante todo o ciclo de vida da construção. 
No Art. $2^{\circ}$. define nove objetivos específicos:

1. difundir o BIM e seus benefícios;

2. coordenar a estruturação do setor público para a adoção do BIM;

3. criar condições favoráveis para o investimento público e privado em BIM;

4. estimular a capacitação em BIM;

5. propor atos normativos que estabeleçam parâmetros para as compras e as contratações públicas com uso do BIM;

6. desenvolver normas técnicas, guias e protocolos específicos para adoção do BIM;

7. desenvolver a Plataforma e a Biblioteca Nacional BIM;

8. estimular o desenvolvimento e aplicação de novas tecnologias ao BIM;

9. incentivar a concorrência no mercado por meio de padrões neutros de interoperabilidade BIM.

Para alcançar estes objetivos, instituiu nos Art. $3^{\circ}$ e $4^{\circ}$ um Comitê Gestor da Estratégia BIM com as seguintes atribuições:

- definir e gerenciar as ações necessárias para o alcance dos objetivos da Estratégia BIM BR;

- elaborar anualmente seu plano de trabalho, que conterá cronograma e estabelecerá as ações prioritárias para o período;

- $\quad$ atuar para que os programas, os projetos e as iniciativas dos órgãos e das entidades públicas que contratam e executam obras públicas sejam coerentes com a Estratégia BIM BR;

- promover o compartilhamento de informações e analisar o impacto das iniciativas setoriais relacionadas a BIM, com vistas à harmonização e à promoção de eficiência e sinergia entre as ações dos órgãos e das entidades públicas;

- acompanhar e avaliar periodicamente os resultados da Estratégia BIM BR e subsidiar as atividades de articulação e de monitoramento de programas de governo da Presidência da República, quando solicitado;

- $\quad$ articular-se com instâncias similares de outros países e dos Estados, do Distrito Federal e dos Municípios;

- expedir recomendações necessárias ao exercício de sua competência;

- deliberar sobre a atualização e a revisão periódica da Estratégia BIM BR;

- opinar sobre temas relacionados às suas competências e elaborar e aprovar seu regimento interno.

No Art.5․ dispõe sobre a composição do CG-BIM, caracterizando-o como um Grupo de Trabalho interministerial, formado por:

- Ministério da Indústria, Comércio Exterior e Serviços;

- Casa Civil da Presidência da República;

- Ministério da Defesa;
- Ministério dos Transportes, Portos e Aviação Civil; Ministério da Saúde;

- Ministério do Planejamento, Desenvolvimento e Gestão; Ministério da Ciência, Tecnologia, Inovações e Comunicações;

- Ministério das Cidades e a Secretaria-Geral da Presidência da República.

Cabendo a coordenação ao Ministério da Indústria, Comércio Exterior e Serviços - MDIC.

Os artigos 6․ ao 13․ dispõem sobre as questões operacionais do CG-BIM, abrindo a possibilidade de criação de Grupos de Trabalho específicos, integrados por consultores especialistas, pesquisadores e técnicos de órgãos e entidades públicas ou privadas.

No Art. $14^{\circ}$. extingue o CE-BIM e no Art. 15․ estabelece a sua vigência imediata, ou seja, desde o dia 17 de maio deste ano, o Brasil tem instituída uma estratégia nacional para disseminação do BIM e um respectivo Comitê Gestor que, dentre outros objetivos, deve coordenar a estruturação do setor público para a adoção do BIM.

A leitura do texto deste decreto revela um instrumento legal de qualidade, capaz de articular os principais agentes públicos envolvidos na difícil tarefa de implementar um processo disruptivo na administração pública, ao mesmo tempo em que busca estabelecer parcerias produtivas com os agentes privados e formaliza a busca pela independência tecnológica ao incentivar a adoção de padrões universais de interoperabilidade.

Constitui-se num excelente pano de fundo para as ações que deverão se organizar a partir daí para tornar efetivos os seus objetivos.

No entanto o seu sucesso dependerá muito da qualidade da gestão pública e da dinâmica futura e grau de maturidade nesta matéria já alcançada pelo setor.

\section{GRAU DE MATURIDADE}

Os parâmetros para avaliação do Grau de Maturidade do desenvolvimento alcançado pelo BIM em Macro Escalas, como a de um país, por exemplo, foram propostos por Succar et al. (2012) sendo composto por oito variáveis:

1. Objetivos, fases e marcos;

2. Publicações de referência;

3. Diretrizes estabelecidas e casos de sucessos;

4. Normas técnicas;

5. Marco regulatório;

6. Indicadores de desempenho;

7. Sistemas de formação e capacitação;

8. Infraestrutura tecnológica.

Este modelo foi aplicado ao contexto brasileiro por Nardelli e Tonso (2014), concluindo-se, então, que o país estava num estágio inicial, com poucas publicações de referência nessa área de fato desenvolvidas no país, marco regulatório incipiente, poucos casos de sucesso e formação e capacitação inexistentes no currículo das escolas de Arquitetura e Engenharia brasileiras, na prática relegados aos cursos de treinamento para o uso de aplicativos BIM.

3 
Visto a partir deste prisma, o cenário atual demonstra uma clara evolução, em particular no que se refere às variáveis 1, 2, 4 e 5, tendo em vista a edição do Decreto 9.377/18, a continuidade dos trabalhos da Comissão de Estudo Especial - ABNT/CEE-134 que, além de promover a atualização da NBR ISO 12006-2:2010 para a atual versão 2018, também atualizou e complementou a NBR 15965-2:2012, que compõe o Sistema de Classificação da Informação da Construção, com o desenvolvimento da versão 2015 e das Partes 1, 3 e 7 e o lançamento das Coletâneas já mencionadas na Introdução.

Com relação à variável 7 , ainda que o ensino de BIM nos cursos de graduação seja uma realidade muito distante, surgiram no Brasil diversas iniciativas no âmbito da Educação Continuada, que vão muito além do mero treinamento no uso de aplicativos, caracterizando-se como cursos de especialização.

Neste sentido, vale mencionar o curso Master BIM Especialista, oferecido pelo ISITEC, sob coordenação da Profa. Dra. Regina Coeli Ruschel, com 380 horas, divididas em dois módulos (ISITEC Inovação e Tecnologia, 2018); o curso de pós-graduação em BIM oferecido pela Faculdade de Tecnologia Alpha Channel, com 360 horas também divididas em dois módulos ( (Faculdade de Tecnologia Alpha Channel, 2018) e o curso Internacional Master BIM Manager, à distância, oferecido pelo Centro Universitário de Brusque UNIFEBE, de Santa Catarina, em parceria com a Zigurat - Global Institute of Technology, com seis módulos, com diferentes cargas horárias, focados nos aspectos de gestão e coordenação de projetos usando o BIM.

Acrescente-se a isso, os diversos trabalhos de Iniciação Científica, Mestrado e Doutorado desenvolvidos nas instituições de ensino e pesquisa, públicas e privadas, ao longo destes últimos quatro anos, além dos trabalhos publicados em Anais de Congressos e Periódicos Indexados.

A este respeito, Ruschel e Lima (2018), identificaram o crescimento da disseminação do BIM em trabalhos acadêmicos, ao analisarem comparativamente os Anais de dois eventos de referência nesta matéria, o ENTAC Encontro Nacional de Tecnologia no Ambiente Construído 2016 e o SBTIC - Simpósio Brasileiro de Tecnologia da Informação e Comunicação na Construção 2017 utilizando neste trabalho as definições de usos do BIM propostas por Succar, Salleb e Sher (2016).

Segundo esta análise a quantidade de trabalhos apresentados sobre BIM praticamente dobra de um evento para outro, registrando um aumento de temas sobre aplicações em operação e manutenção e a vinculação do BIM com SIG e loT e o crescente interesse sobre a introdução do BIM na graduação de Arquitetura e Engenharia. Vale ressaltar, também, a defasagem percebida entre os temas das pesquisas e a prática do uso do BIM pelo mercado: prevalecem estudos associados ao uso em planejamento e projeto, enquanto na prática predomina a adoção do BIM associada à construção. (Ruschel e Lima, 2018)

No entanto, quando se considera a variável 3 - Diretrizes e Casos de Sucesso, verifica-se que a evolução da adoção do BIM no Brasil vive um momento de estagnação, tendo em vista a profunda crise vivida pelo setor de AEC, que interrompeu as contratações de projetos e obras públicas e, do mesmo modo, as atividades do setor imobiliário. (Notícias da Construção, 2015)

Mesmo o fim da recessão econômica brasileira, que alcançou seu pior patamar em maio de 2016, como demonstra o índice de percepção do empresariado em relação à situação corrente dos negócios, não tem sido consistente o suficiente para animar o setor de AEC. (Castelo e Bezerra, 2018)

De fato, o Índice de Confiança da Construção (ICST), da Fundação Getúlio Vargas, avançou 0,7 ponto em março, alcançando 82,1 pontos no primeiro trimestre de 2018 indicando uma alta de 2,9 pontos sobre o trimestre anterior e de 7,2 pontos sobre o mesmo trimestre em 2017. (FGV/IBRE, 2018)

No entanto, de acordo com o recente estudo Impacto Econômico e Social das Obras Públicas no Brasil, feito pela Câmara Brasileira da Indústria da Construção (CBIC), apenas na esfera federal há, aproximadamente, 7 mil obras paradas e, para concluí-las, o governo teria que desembolsar $\mathrm{R} \$ 76$ bilhões. (CBIC, 2018)

Além disso, a sondagem de expectativa das indústrias de materiais de construção realizada pela Associação Brasileira da Indústria de Materiais de Construção ABRAMAT, revela a utilização de apenas $69 \%$ da capacidade industrial instalada na média das empresas de material de construção, em março de 2018, demonstrando ainda folgada ociosidade do parque industrial do setor e baixa expectativa de investimento a curto prazo tendo em vista novas obras. (ABRAMAT, 2018)

Com relação especificamente às empresas de projetos e obras, na realidade, faltam dados mais assertivos acerca do estado da arte das Tecnologias da Informação e Comunicação - TICs, aplicadas ao setor de AEC no Brasil. No entanto, dados da "Sondagem da Construção", realizada pela FGV/IBRE com 700 empresas da construção no país, revelam algumas pistas indicando que o uso do BIM ainda é baixo e bastante desigual entre os segmentos setoriais, já que apenas $9,2 \%$ das empresas consultadas declararam utilizá-lo, sendo o segmento residencial (incluído o setor imobiliário) o que mais utiliza, com $13,9 \%$ do total, seguido por obras de montagem. (Castelo e Bezerra, 2018)

Por outro lado, o relato de casos de sucesso tem demonstrado que o êxito na implementação do BIM nas empresas corresponde ao domínio total do processo, i.e., quando contratante e contratados compartilham o mesmo nível de comprometimento, desde a plataforma utilizada até a metodologia e processos decorrentes, sob a liderança de quem contrata. (O Estado de S. Paulo, 2018)

Cenário bastante improvável nas contratações públicas atuais, particularmente limitadas pela escassez de recursos necessários ao investimento em sua própria capacitação e, principalmente, pelo ambiente definido 
pelo marco regulatório em que precisam atuar, como se pode ver a seguir.

\section{MARCO REGULATÓRIO}

\section{LEI 8.666/93}

No caput do Art. 01, esta lei estabeleceu em 1993 as normas gerais sobre licitações e contratos administrativos pertinentes a obras e serviços no âmbito dos Poderes da União, dos Estados, do Distrito Federal e dos Municípios. Estendendo a sua abrangência, além dos órgãos da administração direta, aos fundos especiais, autarquias, fundações públicas, empresas públicas, sociedades de economia mista e demais entidades controladas direta ou indiretamente pelos três níveis de governo.

Para tanto, criou uma detalhada nomenclatura, ao longo de seus 126 artigos, que constituem o marco regulatório para as contratações, dentre outras, de serviços e obras que, neste caso, só poderão ser feitas a partir de um Projeto Básico, definido no texto legal, Inciso IX do Art.6‥, como sendo:

“(...)conjunto de elementos necessários e suficientes, com nível de precisão adequado, para caracterizar a obra ou serviço, ou complexo de obras ou serviços objeto da licitação, elaborado com base nas indicações dos estudos técnicos preliminares, que assegurem a viabilidade técnica e o adequado tratamento do impacto ambiental do empreendimento, e que possibilite a avaliação do custo da obra e a definição dos métodos e do prazo de execução(...)"

Além disso, no Art.7ํ․ estabelece que as licitações para execução de obras e prestação de serviços de engenharia deverão seguir, necessariamente, a seguinte sequência: I. Projeto Básico; II. Projeto Executivo e III. Execução das Obras e Serviços. E, também, que a execução de cada etapa terá que ser precedida do término da etapa anterior.

No Art. 22. Estabelece como modalidades de licitação a concorrência, tomada de preços, convite, concurso e leilão, definindo-as em seus respectivos parágrafos e, no Art.23. associa cada uma delas a valores de referência.

No Art.45. define os seguintes tipos de licitação: por menor preço, por melhor técnica, por melhor técnica e preço e por maior lance ou oferta - nos casos de alienação de bens ou concessão de direito real de uso.

E, finalmente, no Art. 46., estabelece que os tipos de licitação por melhor técnica ou técnica e preço serão utilizados exclusivamente para serviços de natureza predominantemente intelectual, em especial na elaboração de projetos, cálculos, fiscalização, supervisão e gerenciamento e de engenharia consultiva em geral e, em particular, para a elaboração de estudos técnicos preliminares e projetos básicos e executivos.

No entanto, no inciso II do Parágrafo $1 \%$. deste mesmo Artigo, a Lei determina que após a classificação da melhor proposta, no tipo "melhor técnica", será feita a negociação do preço do objeto contratado com "(...)base nos orçamentos detalhados apresentados e respectivos preços unitários e tendo como referência o limite representado pela proposta de menor preço entre os licitantes que obtiveram a valorização mínima(...)" (Brasil, 1993) (grifamos)

E, mais adiante, no inciso II do Parágrafo $2^{\circ}$. quando se adota o tipo "melhor técnica e preço", a classificação dos proponentes será de acordo com a "(...) média ponderada das valorizações das propostas técnicas e de preço, de acordo com os pesos preestabelecidos no instrumento convocatório." (Brasil, 1993)

Os demais Artigos referem-se a procedimentos operacionais do processo licitatório.

\section{LEI 12.462/2011 - RDC}

No caput do Art. 1‥ esta Lei instituiu o Regime Diferenciado de Contratações Públicas (RDC), com o objetivo de acelerar o processo de contratações do setor público, inicialmente aplicável às obras demandadas pela realização da Copa do Mundo de 2014 e Jogos Olímpicos de 2016, posteriormente estendido às obras e serviços de engenharia do PAC- Programa de Aceleração do Crescimento, do SUS - Sistema Único de Saúde, estabelecimentos penais, infraestrutura logística, mobilidade e ações em instituições dedicadas à ciência, tecnologia e inovação.

O seu grande diferencial em relação à Lei 8666/93 é que ela permite a contratação integrada de serviços e obras, i.e., um mesmo contratado é responsável pela realização dos projetos Básico e Executivo e das respectivas obras, conforme estabelece o Art. 9‥, desde que técnica e economicamente justificada e cujo objeto envolva uma das seguintes condições: inovação tecnológica ou técnica; possibilidade de execução com diferentes metodologias e possibilidade de execução com tecnologias de domínio restrito no mercado.

Neste caso, no entanto, o instrumento convocatório já deverá conter um Anteprojeto de engenharia, com os documentos técnicos caracterizando a obra ou serviço, incluindo a demonstração e a justificativa do programa de necessidades, a visão global dos investimentos e as definições quanto ao nível de serviço desejado, a estética do projeto arquitetônico e os parâmetros de adequação ao interesse público, à economia na utilização, à facilidade na execução, aos impactos ambientais e à acessibilidade.

Com relação aos critérios de julgamento das propostas apresentadas pelos licitantes não difere muito da Lei

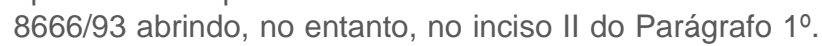
do Art.20. a possibilidade de utilização de parâmetros objetivos de ponderação da qualidade técnica das propostas de objetos que possam ser executados com diferentes metodologias ou tecnologias de domínio restrito no mercado, pontuando-se as vantagens e qualidades que eventualmente forem oferecidas para cada produto ou solução.

Além disso, permite a contratação de projetos arquitetônicos e trabalhos de natureza técnica, científica ou artística, à exceção de projetos de Engenharia, pela melhor técnica ou pelo melhor conteúdo artístico com base em critérios objetivos previamente estabelecidos no instrumento convocatório, independentemente do valor do
5 
prêmio ou a remuneração correspondente, que estará definido no respectivo edital.

\section{LEI 13.303/2016 - ESTATAIS}

No caput do Art.1ํ. esta Lei dispõe sobre o estatuto jurídico da empresa pública, da sociedade de economia mista e de suas subsidiárias, abrangendo toda e qualquer empresa pública e sociedade de economia mista da União, dos Estados, do Distrito Federal e dos Municípios que explore atividade econômica de produção ou comercialização de bens ou de prestação de serviços, ainda que a atividade econômica esteja sujeita ao regime de monopólio da União ou seja de prestação de serviços públicos.

Foi aprovada em 30 de junho de 2016, em meio aos escândalos de corrupção e desmandos na administração pública com o objetivo de coibir desvios e abusos na gestão dessas empresas.

O regramento referente à contratação de serviços e obras encontra-se na Seção I, a partir do Art.28. e estende-se até a Seção III, Art. 46. criando uma nomenclatura própria, ao invés de referir-se àquela já definida nas duas leis pré-existentes que tratam deste mesmo tema.

Em síntese, obriga a realização de licitações para a contratação de serviços e obras cujo valor de referência seja superior a $\mathrm{R} \$ 100.000,00$ - reajustáveis de acordo com a evolução da inflação - com exceções específicas.

Admite a contratação por empreitada integral, semiintegrada e integrada, casos em que o contratado terá que desenvolver o projeto Básico e o Executivo - cujas definições são idênticas às das Leis mencionadas anteriormente -, a partir de um Anteprojeto, que será utilizado como referência para a formação do preço do trabalho contratado, como no caso da Lei $12.462 / 11$ do RDC.

Nos demais artigos este documento legal trata da estrutura administrativa e de governança dessas empresas.

\section{DISCUSSÃO}

Pelo exposto anteriormente, é possível constatar que a adoção do BIM no Brasil experimentou uma grande evolução institucional nesta segunda década dos anos 2000, notadamente no que se refere ao marco regulatório, com o avanço lento, porém contínuo, dos trabalhos da Comissão de Estudo Especial - ABNT/CEE134, no esforço de elaboração da NBR - ISO 120062:2018 e da NBR 15965-1,2, 3 e 7:2015.

Pode-se dizer que esta evolução institucional se consagra com a edição do recente Decreto 9.377/18, que institui a Estratégia Nacional de Disseminação do Building Information Modelling no Brasil - Estratégia BIM BR, para promover um ambiente adequado ao investimento em BIM e sua difusão no País, tendo como um de seus objetivos coordenar a estruturação do setor público, o maior contratante brasileiro do setor de AEC, para a adoção do BIM, ainda que não fixe em seu texto uma data de referência para a finalização deste processo.

Também vale registrar a evolução da disseminação do conhecimento BIM, caracterizada pelo lançamento por relevantes instituições do setor de consistentes publicações sobre o tema e pela intensa produção acadêmica, através de trabalhos de Iniciação Científica, Mestrados, Doutorados e artigos em eventos e publicações indexadas de referência no setor de AEC.

Do mesmo modo, constatamos a oferta recente de cursos de especialização em Gerenciamento BIM, que vão além da simples capacitação na utilização de aplicativos específicos.

No entanto, quando analisamos o atual cenário onde a prática do BIM deve acontecer, percebemos que o país vive um momento de grande estagnação da atividade econômica em geral que afeta, em particular, o setor de $A E C$, indicando que os principais atores desse processo demandarão ainda um longo tempo para se adaptarem e se capacitarem para tornar realidade aquilo que o Decreto 9.377/18 propõe.

Mais ainda quando se considera o pano de fundo do marco regulatório das contratações públicas que ainda se referem ao modo tradicional de desenvolvimento de projetos e obras e, mesmo neste caso, de forma equivocada, estabelecendo regras onde prevalece 0 critério de menor preço para escolha do trabalho contratado e, em nenhum momento, se refere ao Projeto Executivo Completo, que integre todas as disciplinas que envolvem a produção de um espaço construído, paradigma fundamental do BIM.

Além disso, a partir do momento em que se supera o paradigma da representação e se adota a modelagem virtual da construção como referência, faz sentido que as licitações continuem a seguir o padrão Design-Bid-Build i.e., Projeto, Licitação e Construção, conforme estabelecido no Art.7º da Lei 8666/93 - ou evoluiremos definitivamente para o padrão Design-Build - i.e. equipe de Projeto e Obra contratados de forma integrada -, conforme proposto pelas Leis 12.462/2011 e 13.303/2016? (Eastman et al., 2008, p.4-8)

Como considerar, então, a adoção do BIM pelo setor público sem levar em conta, por exemplo, a dinâmica do IPD - Integrated Project Delivery, que prevê a atuação colaborativa entre os profissionais que desenvolvem os projetos complementares que compõem o Projeto Executivo Completo? Como seria feita a remuneração dessa equipe, de acordo com os atuais parâmetros legais para estruturação das licitações? (AIA, 2007)

E como serão definidos os produtos entregáveis se a legislação atual se refere às normas da $A B N T$, que estabelecem os parâmetros para as atividades técnicas de Arquitetura e Engenharia exigíveis para a construção com base no processo tradicional de concepção e desenvolvimento de projetos e, em nenhuma delas, está estabelecido, por exemplo, o nível de detalhamento (LOD - Level of Development) correspondente a cada etapa do projeto? (Santa Catarina, 2014) 
Já se vê, portanto, que apesar dos grandes avanços alcançados, ainda há um longo caminho a percorrer, notadamente na redefinição do marco regulatório das contratações públicas de projetos e obras à luz do BIM.

\section{CONSIDERAÇÕES FINAIS}

É inegável o avanço institucional da adoção do BIM no Brasil, no entanto e apesar disso, ainda há um longo caminho a ser percorrido na superação de diversas barreiras.

A mais importante delas, seguramente, é a revisão de todo o marco regulatório para a contratação de projetos e obras no país onde, atualmente, estão em vigência três leis que se sobrepõem, tratando do mesmo tema, sempre a partir do modo tradicional de produção de projetos e construção, baseado no paradigma da representação geométrica dos elementos que compõem o espaço construído e não na modelagem virtual da construção.

O novo paradigma, introduzido pelo processo BIM, tem nomenclatura e processos próprios que são disruptivos em relação às referências atuais e a sua implementação tem o potencial de provocar um necessário redesenho da estrutura do Estado brasileiro, pelo menos no que se refere à produção pública do ambiente construído.

Neste sentido, pode ser uma boa oportunidade de saneamento de práticas que se revelaram nefastas tanto para a evolução técnica e tecnológica do país, quanto ao interesse público.

No entanto, a efetiva adoção do BIM pelos principais agentes, públicos e privados, também passa pela solução de diversos gargalos que têm impedido a retomada do desenvolvimento econômico do país.

Sem ter uma noção clara dos custos envolvidos nessa migração e das possibilidades e prazo de retorno do investimento necessário para essa transição, dificilmente os atores chave desse processo se comprometerão com esta profunda transformação.

\section{REFERÊNCIAS}

ABDI, 2017. Agência Brasileira de Desenvolvimento Industrial. Classificação da Informação no BIM: Coletânea Guias BIM ABDI-MDIC/Agência Brasileira de Desenvolvimento Industrial. 6 V. - Brasília, DF - Disponível em http://www.abdi.com.br/Paginas/bim_construcao_cadastro.as px - Acesso em 25/06/2018

ABNT - Associação Brasileira de Normas Técnicas, 2018. NBR ISO 12006-2:2018. Construção de edificação - Organização de informação da construção Parte 2: Estrutura para classificação. Brasília, DF, junho 2018

ABNT - Associação Brasileira de Normas Técnicas, 2018. NBR 15965:2015. Sistema de classificação da informação da construção. Brasília, DF, junho 2018

ABRAMAT, 2018. Associação Brasileira da Indústria Materiais de Construção. Termômetro ABRAMAT - março/2018 Sondagem de expectativas das indústrias de materiais de construção. Disponível em http://az545403.vo.msecnd.net/observatoriodaconstrucao/20 17/09/Termometro_Imprensa_03_2018.pdf - Acesso em 22/06/2018
AIA, 2007. Integrated Project Delivery: A guide - American Institute of Architects California Council. May 15, 2007. Disponível em: https://info.aia.org/SiteObjects/files/IPD_Guide_2007.pdf Acesso em 25/06/2018.

Anais [do] 1o Simpósio Brasileiro de Tecnologia de Informação e Comunicação na Construção (SBTIC 2017) [livro eletrônico] / organizadores: Sergio Scheer, Eduardo Toledo Santos, Mariana M. Xavier de Lima. Fortaleza, CE: Marketing Aumentado, 2017.

BRASIL. Lei № 8.666, de 21 DE JUNHO de 1993. Regulamenta 0 art. 37, inciso XXI, da Constituição Federal, institui normas para licitações e contratos da Administração Pública e dá outras providências. Disponível em: http://www.planalto.gov.br/ccivil_03/Leis//8666cons.htm Acesso em 22/06/2018

BRASIL. Lei № 12.462, de 4 de agosto de 2011. Institui o Regime Diferenciado de Contratações Públicas - RDC e dá outras providências. Disponível em: http://www.planalto.gov.br/ccivil_03/_ato20112014/2011/lei/l12462.htm - Acesso 25/06/2018

BRASIL. Lei $n^{\circ}$ 13.303, de 30 de junho de 2016. Dispõe sobre o estatuto jurídico da empresa pública e dá outras providências. Disponível http://www.planalto.gov.br/ccivil_03/_ato20152018/2016/lei//13303.htm - Acesso em 25/06/2018

BRASIL. Decreto 14.473/2017 de 05/06/2017. Institui o Comitê Estratégico de Implementação do Building Information Modelling. Brasília, DF, junho 2017.

BRASIL. Decreto n. 9.377, de 17 de maio de 2018. Institui a Estratégia de Disseminação do Building Information Modelling. Diário Oficial da União, Brasília, Edição 95, Seção 1, p. 3, mai. 2018. Atos do Poder Executivo.Brasil.

Castelo, Ana Maria e Bezerra, Itaiguara, 2018. A construção digital. Disponível em http://blogdoibre.fgv.br/posts/construcao-digital - Acesso em 22/06/2018

CBIC - Câmara Brasileira da Indústria da Construção, 2018. Impacto econômico e social da paralisação das obras públicas. CBIC - Câmara Brasileira da Indústria da Construção/Inter.B - Consultoria Internacional de Negócios, 2018, 76 p.

EASTMAN, Chuck et alli - BIM HANDBOOK - A guide to Building Information Modeling for Owners, Managers, Designers, Engineers and Contractors - John Wiley and Sons, Inc., 2008

Fundação Getúlio Vargas - FGV/Instituto Brasileiro de Economia - IBRE, 2018. Confiança da Construção avança em março. 26/03/2018. Disponível em http://portalibre.fgv.br/main.jsp?lumPageld=402880972283E 1AA0122841CE9191DD3\&contentld=8A7C82C561E9052D0 16261CE4A290116 - Acesso em 22/06/2018

G1, Globo, 2015. Construção civil vai demitir mais de meio milhão de trabalhadores. Disponível em http://g1.globo.com/bom-dia-

brasil/noticia/2015/09/construcao-civil-vai-demitir-mais-demeio-milhao-de-trabalhadores.html . Acesso em 15/06/2018

Nardelli, Eduardo Sampaio (2012) Desafios do Programa Minha Casa Minha Vida frente ao processo BIM - Building Information Modeling: migrando para O IPD - Integrated Project Delivery [BIM process challenges of My Home My Life Program: migrating to IPD - integrated project delivery] SIGraDi 2012 [Proceedings of the 16th Iberoamerican Congress of Digital Graphics] Brasil - Fortaleza 13-16 November 2012, pp. 505-508. Disponível em http://papers.cumincad.org/cgibin/works/Show?sigradi2012_250 - Acesso em 25/06/18

Nardelli, Eduardo Sampaio; Lais Guerle Tonso (2014) BIM Barreiras institucionais para a sua implantação no Brasil [BIM - Institutional barriers to its implementation in Brazil] SiGraDi 
2014 [Proceedings of the 18th Conference of the Iberoamerican Society of Digital Graphics - ISBN: 978-997499-655-7] Uruguay - Montevideo 12 - 14 November 2014, pp. 408-411 Disponível em http://papers.cumincad.org/cgibin/works/Show?sigradi2014_292 - Acesso 25/06/2018

Notícias da Construção, 2015. Céu Azul Desaparece do Horizonte. In: NOTÍCIAS DA CONSTRUÇÃO, set. 2015, no. 148, p. 6-13. Disponível em https://www.sindusconsp.com.br/wp-

content/uploads/2015/10/Ed148-set2015-final.pdf . Acesso em $22 / 06 / 2018$

PROCESSOS inovadores já mudam desempenho de empresas brasileiras. O Estado de S. Paulo, 22/03/2018, Caderno Especial Tecnologia na Construção, p. 2, 2c.

Ruschel, Regina C. e Lima, Mariana M. X. de, 2018. O potencial de contribuição da academia na difusão do BIM. Disponível em https://cbic.org.br/o-potencial-de-contribuicao-daacademia-na-difusao-do-bim/ . Acesso em 22/06/2018.

Santa Catarina. Secretaria De Estado da Saúde. Termo de Referência para desenvolvimento de projetos com o uso da Modelagem da Informação da Construção (BIM). Março 2014 $-$ Disponível

https://www.bndes.gov.br/SiteBNDES/export/sites/default/bn des_pt/Galerias/Arquivos/empresa/licitacoes/Tomadas_de_P recos/tp0415_anexolX.pdf - acesso em 13/06/2018

SECOVI, 2011 - A importância da inovação tecnológica para fortalecimento do mercado imobiliário. Disponível em http://www.secovi.com.br/noticias/a-importancia-da-inovacaotecnologica-para-fortalecimento-do-mercado-imobiliario/4035 - Acesso em 25;06/18

Succar, Bilal, Willy Sher \& Anthony Williams (2012) Measuring BIM performance: Five metrics, Architectural Engineering and Design Management, 8:2, 120-142
Succar, B.; Saleeb, N.; Sher, W. Model uses: foundation for a modular requirements clarification language. In: Australasian Universities Building Education Association Conference, 40., 2016, Cairns. Proceedings ... Rockhampton: Central Queensland University, jul. 2016. p. 45-57. Disponível em: https://espace.library.uq.edu.au/view/UQ:396629/UQ396629 frontmatter.pdf. Acesso em: 29/05/2018.

Toledo, Eduardo S. - BIM: transparência e controle. O Estado de São Paulo, 11/03/2018, p.4 c. Imóveis

UK, 2016. Embaixada Britânica Brasília, Department for International Trade Brazil, e Consulado Geral Britânico São Paulo. Ministro do Comércio Internacional assina MoU com MDIC. Disponível

https://www.gov.uk/government/news/sos-liam-fox-signsmou-with-mdic.pt - Acesso em 15/06/2018

SINAENCO, 2018 - BIM, uma solução e novos desafios. Disponível em http://sinaenco.com.br/noticias/bim-umasolucao-e-novos-desafios/ - Acesso em 19/06/2018

Sites

http://www.isitec.org.br/nossos-cursos/master-bim-especialista2018/ - Acesso em 21/06/2018

http://www.alphachannel.net.br/posgraduacao/posalpha/arquitetura/bim-para-arquitetura-e-engenharia-civil acesso em 21/06/2018

https://www.e-zigurat.com/br/home/home-general/general-3/ Acesso em 21/06/2018

http://www.unifebe.edu.br/site/cursos/posgraduacao/ead/internacional-master-bim-manager/ - Acesso em 21/06/2018 